\title{
(Anti)Hermeneutical Philosophy for Science
}

\author{
Evaldas Juozelis \\ Mykolas Romeris University, Philosophy Department
}

\begin{abstract}
Philosophical hermeneutics claims that human understanding, while being contingent and historical, is likewise universal and bears within itself some pervasive features detectable via hermeneutical analyses of historically imparted tradition and language. Similarly, hermeneutical philosophy of science is confident that hermeneutical methods are the only proper tool to adequately assess, reconstruct, explain or give a meaning to historical but universal scientific knowledge and its various forms. I point out two versions of hermeneutical philosophy of science and argue that whenever philosophical hermeneutics pursues rescuing "scientificity", human rationality, human rights, common values, and so forth under the pretence of its universality and competence, it necessarily transcends and violates the tenets of its own. I conclude in the favour of moderate interpretation of practical hermeneutics, perhaps in the very essence of it rest postmodern concepts of historicality, transparency and tolerance, without which there is no possibility of extricating oneself from hermeneuticism.
\end{abstract}

Keywords: hermeneutical philosophy of science, neopragmatism, philosophy of scientific practices, P. Heelan, D. Ginev, J. Rouse

1.

Well-known hermeneuticists Robert Crease, Patrick Heelan, Martin Eger, Don Ihde and others gave great efforts to assess the impact of hermeneutical thought to the mainstream philosophy of science and to associate hermeneutical philosophy with natural sciences and technology. To present their research even in the briefest form would not be appropriate here, moreover, I cast no doubts on the importance of hermeneutics' ambition to supply "the philosophical foundation for reintroducing history and culture into the philosophy of the natural sciences" and I acknowledge its merits introducing and anchoring the idea that "scientific knowledge [...] deals with meanings

Corresponding author's address: Evaldas Juozelis, Mykolas Romeris University, Philosophy Department, Ateities 20, LT-08303, Vilnius, Lithuania. Email: ejuozelis@mruni.eu. 
that are social entities, embodied in language, altered or fulfilled in experience, and passed on in laboratory praxes and scientific literature and culture" (Crease 1997, 259). Therefore in this paper I intend to focus not on the common ground of hermeneutical philosophy of science, but on the particular hermeneutical interest, namely, "the role that hermeneutical philosophy could play in understanding science" (Crease 1997, 259). If according to Crease science has a historical space, or "here and now," "with its own reference to an (historical) authenticating judge and witness", it is unclear, though, what the aforementioned "reintroduction" of history and culture into the philosophy of science is supposed to mean: A) a proposal to restore the previously rejected idea of science as a socio-historical enterprise that lends priority to language and experience (in other words, that scientific understanding, at least in part, is hermeneutical and phenomenological), or yet B) a more rigid demand to show that the validity or confidence of scientific knowledge is based upon a philosophical-hermeneutical core or foundation.

In section II, I outline Heelan's issue on relation between philosophical hermeneutics and natural science and point out that despite his attempt to proclaim a relatively neutral image of hermeneutics towards natural science, Heelan perhaps undeliberately engages a mode of foundationalist philosophical regime as a legitimating basis of scientific knowing. In section III, I consider Dimitri Ginev's version of philosophical hermeneutics compared to philosophy of scientific practices of Joseph Rouse and suggest that to thoroughly understand the diverse modes of intertwining of hermeneutics and science one should invoke a "politically" biased philosophical framework that is more apt to disclose an adequate picture of science as a cultural and social entity. In section IV, I state that in my interpretation Rouse's as well as Rorty's attitude cannot be set in any version of hermeneuticism, since differently from all sorts of hermeneuticism it purports an ongoing questioning of any philosophical foundations on the grounds of practical, political milieu.

\section{2.}

Referring to Heelan, Crease stresses that Edmund Husserl criticized not science itself, but the Galilean assumption that mathematics alone provides the ontology of nature, thus bypassing the life-world; what follows is that Husserl (and later Martin Heidegger) diagnose "a historical crisis which they attributed to the hegemonic role of theory in the arbitration of meaning, the effacement of the role of the embodied human subjects in the constitution of knowledge, and the implicit assumption, characteristic of modernity, that the natural sciences provide the privileged model for human inquiry" (Crease 1997, 259-260). Supposedly it illustrates the hereinbefore stated play of hermeneutical philosophy in understanding science, neverthe- 
less the hermeneutical role playing remains ambiguous. By this hermeneutical reintroducing we are inclined to acknowledge that there is something deeply wrong with our understanding; but is that understanding scientific or philosophical-hermeneutical? What or who (if we vindicate the role of the embodied human subjects) constitutes knowledge? Intuitively one would expect (as the intimate logic of an argument implies) that any phenomenological hermeneuticist would aim at restoring the once lost ontological significance of natural sciences, for instance, by incorporating "into the philosophy of science those aspects of historicality, culture, and tradition that are absent from the traditional analysis of theory and explanation", and/or by re-orientating "the current discussion about scientific realism around the hermeneutics of meaning and truth in science" (Heelan 1998, 273). But more importantly, Heelan insists that "we do not ask of a philosophy that it contribute to the successful practice of science" (Heelan 1998, 293). So what is at issue here is the engagement of hermeneutical thinking into scientific practices. If there is a hermeneutics of science, i.e. scientific knowledge functions, at least to some extent, hermeneutically (option A above) (as Crease puts it: "The days are gone when it could be seriously debated whether a hermeneutical perspective on the natural sciences exists" Crease 1997, 261), an appropriate issue would be not the problematization of the possibility of a hermeneutics of natural science, but the mode of its engagement, or a type of intertwining of hermeneutics and science.

In another paper Heelan (in symbolic tandem with Jay Schulkin) discusses "a political society such as ours". He warns that

it may be a mistake to suppose that the current questioning of the agenda of scientific culture by public agencies and media indicates a 'flight from rationality' or a lapse of public confidence in scientific knowledge, rather than a general failure of public institutions including scientific ones to present a believable culturally attuned and historical account of science. (Heelan and Schulkin 1998, 294)

Thus, the abovementioned re-orientation is seemingly not just a formal intellectual posture, but a practical and political (in a broader sense-as a strategy of a certain human activity and thinking as well as a setting of material and social technologies) move. Moreover, it requires a particular responsibility, or accountability, the subtlety of which Thomas Kuhn, in Heelan's eyes, failed to identify:

He failed, however, as most others have failed too, to give a good philosophical account of historical theory change and the cultural construction of scientific entities. Hermeneutical philosophy and a hermeneutically sensitive pragmatism could fare better $[\ldots]$ together 
with the social and cultural studies of science. Such an accomplishment would provide elements for a better scholarly and public appreciation of what is certainly one of the greatest institutions of our society. (Heelan and Schulkin 1998, 294)

So, do we need or not a (hermeneutical) philosophy that contributes to the successful practice of science? The answer is quite obvious. Heelan corroborates the demand in the following words:

In this work [to construct and interpret the meaning of scientific understanding] lies the significance and power of hermeneutic method and hermeneutic philosophy for the history and philosophy of science. And not just for these, but also for understanding how quantitative empirical methods function in science to give meaning to empirical contents, in particular, how measurement equipment plays a double role creating both theoretical and cultural meanings, and how theory-laden data depend on the successful public self-presentation in measurement of the measured entity as a public cultural entity. [...] Interpretative work of this kind is clearly historical, cultural, and anthropological, multidisciplinary in character and in need of a philosophical foundation which hermeneutical philosophy [...] tries to provide. (Heelan 1997, 278, italics mine)

In the same article and in the paper written with Schulkin for the journal Synthese about the desirable synthesis of hermeneutics and pragmatism, Heelan conclusively stresses the fact that

so-called 'theoretical entities' are naturalizable in the lifeworld through science-based technologies and thereby become public cultural and perceptual entities. These principles [of hermeneutic method as a process] which span both pragmatism and hermeneutical philosophy can found a new empiricism and restore kinship with the scientific revolution that began not with Descartes or Boyle, but with the empiricism of Galileo. (Heelan and Schulkin 1998, 294)

It does not seem to me after all that here we deal with an unpretentious collaboration of philosophical and scientific discourses. What is under way is not a kind of restoration of "historical justice" concerning continental philosophy of science that Crease (regretting about the unexplored hermeneutical pole of a hermeneutic-positivist binary as a potential resource) had in mind, but the shift (or revolution) in the scientifically-philosophical discourse itself. The so-called weaknesses of the positivist-inspired understanding of science are being compensated here not by Crease's good-willing deeper appreciation of hermeneutical dimensions of sciences, but by imposing a kind of "naturalized" version of sophisticated pragmatistic/new empiricist thinking with a flavour of politically biased partiality. In other words, 
hermeneutical discourse proposed by Heelan allegedly regiments the rules of the intellectual play among various scientifically inclined philosophical narratives, and does so with a permission of its "hermeneutical method" (recall that "interpretative work of this kind" is not only in need of a philosophical foundation, but that the foundation in need is hermeneutical) or actually by sanctioning and self-legitimizing its own universality (option B above). What is needed in addition is just to clothe any possible rival in hermeneutical dress, and all potential opposition seemingly disappears.

\title{
3.
}

If I am right at least in part, then it possibly sheds some light on Dimitri Ginev's attitude towards Heelan's initiative. Ginev writes:

\begin{abstract}
Like many 'internal critics' of the analytical tradition, Heelan blames the mainstream philosophy of science for neglecting the social-historical-instrumental context of scientific practices. Strangely enough, he invests more efforts in criticising Continental philosophy's pictures of science. Traditional hermeneutic phenomenology and philosophical hermeneutics fail to see that scientific research discloses 'new perceptual horizons'. The critique of science in terms of a hermeneutic ontology of laboratory research practices is a criticism of scientism as 'objectivist ideology' of modern science. By no means, however, this critique would tolerate an ideological attack on scientific practices. (Ginev 2006, 66-67, italics mine)
\end{abstract}

But it is not strange at all, if one considers the scope and depth of the hermeneutical project. Recall Heelan's interpretation of Husserl's objection to the Galilean assumption that the ontology of nature is provided by mathematics. Husserl and Heidegger could not recognize how important and revolutionary the hegemonic role of theory in the arbitration of meaning really was, and how necessary is finally to restore the so-called new ("strong") hermeneutic empiricism of Heelan. What else is it if not a characteristically modern approach that the natural sciences provide the privileged model for human inquiry? Husserl, Heidegger, and especially Gadamer were too cautious and too little scientific in "hermeneutically naturalizing" (i.e. in restoring the ontological significance of natural sciences, in incorporating into the philosophy of science conceptual frameworks of historicality, culture and tradition, in re-orientating scientific realism around the hermeneutics of meaning and truth in science and re-establishing the relationship between the current philosophy of natural science and hermeneutical philosophy, as Heelan intends to do) the natural realm.

Moreover, I think Ginev hits the nail on the head issuing another aspect of the quandary: namely its ideological charge. I refer to Richard Rorty: 
'[H]ermeneutics' is not the name for a discipline, nor for a method of achieving the sort of results which epistemology failed to achieve, nor for a program of research. On the contrary, hermeneutics is an expression of hope that the cultural space left by the demise of epistemology will not be filled-that our culture should become one in which the demand for constraint and confrontation is no longer felt [...] We must be hermeneutical where we do not understand what is happening but are honest enough to admit it, rather than being blatantly 'Whiggish' about it. This means that we can get epistemological commensuration only where we already have agreed-upon practices of inquiry (or, more generally, of discourse) - as easily in 'academic' art, 'scholastic' philosophy, or 'parliamentary' politics as in 'normal' science. [...] If we draw the line between epistemology and hermeneutics as I have been drawing it-as a contrast between discourse about normal and about abnormal discourse-then it seems clear that the two do not compete, but rather help each other out. [...] Hermeneutics is not 'another way of knowing' - 'understanding' as opposed to (predictive) 'explanation'. It is better seen as another way of coping. (Rorty 1979, 315, 321, 346, 356)

Rorty's interpretation of hermeneutics is also quite obviously politically ("ideologically") defined, but by the same token it underlines matters of tolerance: it concerns democratic ideals of freedom, equality and selfexpression ("liberal democracy"). If according to Rorty hermeneutics is an intellectual platform absent of constraint and confrontation, it necessarily contributes to democratization processes as an edifying discourse. The important question is how tolerant the hermeneutical platform has to be and to what degree it itself is tolerable. As the saying is the only constraint on the principle of tolerance is non-tolerance of intolerants. There always is a spot or point or mark in the intellectual structure that is vulnerable, in this instance-the historicality of hermeneutical initiative.

Hermeneutics thus aligns itself with radically democratic politics, since it denies that we can find security or grounding for our particular interpretation of what achieving our country involves. In particular, it denies that we can look to ahistorical notions of human rights, which serve only to limit in advance the options available for our future. [...] Here, however, Rorty misses an opportunity within our hermeneutic situation that his own appeal to hermeneutics illuminates. The use Rorty makes of Gadamer suggests that because we are thrown into a history and a vocabulary, neither of which we can escape without losing our framework of understanding, we can revise and reconsider that framework only through a process of Bildung that involves examining our assumptions from within, in terms of what we understand of and from others. [...] For this reason, it would seem that hermeneutics requires the fullest range of perspectives possible 
and, perhaps ironically, it has to be wary precisely of those that would seek to restrict this range. (Warnke 2003, 116)

Whether Rorty in fact misses the opportunity given by hermeneutics to reconsider and critically evaluate those elements of philosophical discourse that obviate alternative ways of "coping", is another matter, but I guess it echoes precisely the situation I want to elaborate concerning Heelan's and Ginev's hermeneuticism. As a constant follower of the former, Ginev by no means, but in his own way would tolerate any critique of hermeneutical reason, because straightforwardly identifies it with "ideological" attack, as if hermeneutics itself represents some "natural kind" of ahistorical philosophical interpretation.

And here Ginev's attack on Joseph Rouse's "politics of postmodern philosophy of science" is quite informative. To cut a long story short, Rouse's philosophy of scientific practices is a conceptual model of an engagement in scientific practices and their political significance that implies that a politically-oriented human self-consciousness is detectable even in a specific medium formed by those practices. This kind of discourse refers to itself as a scientific self-identity being directed towards practico-theoretical understanding of science, which can also be evaluated as a political undertaking (Rouse 1991, 1996, 2002). Ginev $(2005,2006)$ opposes to this kind of "politics" and alerts that the successive destruction of the cognitive autonomy of science poses a threat to the democratization processes of modern societies. Ginev's version of phenomenological hermeneutics (namely, cognitive existentialism) lays claims to having discovered a new "philosophical identity" of science beyond scientism, essentialism and representationism, but unlike the "postmodern policy" trend of philosophy of scientific practices hopes to develop a philosophical program for science, which is to be achieved through an internal (hermeneutic) reflection upon scientific practices (option B), and not by means of imposing, so Ginev argues, external aims of social and cultural criticism, thereby gently opposing Rouse's habit to not clearly separate the content of science disciplines and its outward social and cultural assessment (option A above).

But what are the "internal" mechanisms of scientific "democratization"? The argument goes as following: Rouse does not suggest an adequate philosophical framework for addressing the issue of the contextuality of scientific knowledge within the dynamics of scientific practices and fails to understand scientific practices philosophically, because his conception does not have the resources to give accounts of the interpretative constitution of science's theoretical knowledge that resists structural changes through its ongoing "recontextualization". His deflationary accounts do not suggest genuine arguments against science's epistemic autonomy and his move from prag- 
matic deflationism (which " provides accounts of how the sciences can be developed freely, without arbitrary constraint") to a kind of naturalism does not provide a remedy for removing this deficiency; but precisely the philosophical reflection does reject deflationism and implies an antiessentialist defense of science's cognitive specificity and epistemic autonomy (Ginev 2005, 193). I think Ginev is right that there is a political moment involved in Rouse's claim that the contextuality and situatedness of the practices themselves suffice to understand them and that anybody who has a social-pragmatic relation to the particular contexts and situations in which these practices take place (i.e. anybody who is involved in a certain epistemic alignment) may participate in the 'local assessments' of the epistemic status of scientific activities and achievements, that is the deflationary accounts offer the opportunity for assessing scientific knowledge in a democratic manner (Ginev 2005, 194). As Steve Fuller once noticed, "for Rouse, 'science' lies in the composite generative capacity of the individuals who recognize each other as scientists".

[I]f the current members of the scientific community came to test their hypotheses against the scores of football matches and were satisfied with the results, and the larger society continued to defer to the scientists' authority, then betting on football matches would constitute scientific experimentation. (Fuller 2003, 476-475)

Sticking to the point, Ginev captures Rouse's expression of "normative anaemia", meaning

the lack of resources needed to criticize specific scientific practices on the grounds of their own arguments and concerns. In contrast to the anormative descriptivism of mainstream philosophy of science, a normative criticism of scientific practices would change-so Rouse's argument goes-the status of the sciences within the public sphere. Consequently, the politics of postmodern critical engagement with the sciences opposes all philosophical programmes that are not equipped to enquire into the role the sciences play in the public sphere (Ginev 2005, 195).

What follows next is Ginev's confession that after all the honest efforts he had not found "in Rouse's publications even an example that shows how, within scenarios of cultural studies, a normative criticism of scientific practices can overcome the normative anaemia" (Ginev 2005, 195). Why? I suspect that the initial obstacle is the misrecognition of the politics of postmodern philosophy of science (and eventually cultural studies of science) as a philosophical program, but rather as a new "political-normative attitude". This implication rests upon Ginev's cognitive existentialism which inherently dismantles all the discourses of postmodern kind as eclectic and 
unfounded. The second reason rests on Ginev's effort to impute to Rouse a populist position of Paul Feyerabend, according to whom the state-funded science must be accountable to the state or its representatives- "committees of laymen". However, this claim totally distorts Rouse's concepts of practices as "epistemic alignments" and "patterns of situated activity". The third reason lies in Ginev's category of "politics": he ignores the fact that Rouse explicitly claims that at certain stages of practico-theoretical elaboration political, epistemic, ethical, and other statements are of equal importance on the basis of power-knowledge dynamics. That is, alignments of power without components of knowledge (and vice versa) are unintelligible, but it does not say that they can be reduced to one another, as if a scientific statement would inevitably be a political manifesto.

And finally, the fourth reason of Ginev's "anaemia": I feel a little confused by his criticism that Rouse's normativism does not exhibit any positive outcome for the socio-cultural medium. Properly speaking, you may require something similar of "unphilosophical", ideologically and pragmaticallyminded doctrine, but Ginev also frankly admits that the essence of cognitive existentialism ("- - a conception that treats science as a dynamics of research practices in which cognitive content is constituted and 'situated' within open (practical and theoretical) horizons of doing research", Ginev 2007,68 ) is best disclosed by Nicholas Rescher's tenet of "objective pragmatism" ("Objective pragmatism, as it is developed by Rescher, defends [science's cognitive] specificity in terms of a theory of the process of rational selection in cognitive evolution", Ginev 2007, 58) and its "anti-ideological" stance that would likely resist the legitimizing narrative. If Rouse and Rorty promote subjective pragmatism (which is still to be recognized as a politicalnormative attitude, rather than the program of research) and nevertheless are required to deliver some tangible results, is the objective pragmatism an exception? I did not find in Ginev's texts even an example.

\section{4 .}

Regretting that the edifice of Rouse is so irrelevant to the scientific research, Ginev admits that non-radical versions of antiessentialism (i.e. cognitive existentialism) fail to defeat the circular argument in the form of petitio principii, and to a certain extent circularity is unavoidable in any strategy of defending science's cognitive specificity. So the task of any trustworthy hermeneutical strategy is not to eliminate circularity radically, but rather to reformulate it as a hermeneutic circle "that can come to grips with the intrinsic circularity of the interplay between 'practical theorizing' (carrying out particular research practices, which are theory-laden) and 'theoretical praxis' (articulation of cognitive content by realizing possibilities embedded 
in the interrelatedness of practices) in a scientific domain" (Ginev 2007, 71). Here at the end we are supposed to realize where the cognitive specificity comes from: "The cognitive organization of this research process is therefore shaped by the epistemology and methodology of the interpretive thematization and the intrinsic rhetoric of the interpretive self-refiection" (Ginev 1998, 264). But Ginev is familiar with Rouse's and Mark Okrent's notice that the argument from the self-interpreting status of human beings as cultural agents to the special cognitive structure of the human sciences is a non sequitur, and is fair enough to admit again, that self-interpretation is a part of each mode of cultural existence and it does not follow "that the sciences which deal with the cultural manifestations of human beings must have a different cognitive structure as compared with other types of science. There is only a pragmatic difference between the interpretive activities..." (Ginev $1998,263)$. If this is the case, then Rouse should return the complaint back to Ginev and ask whether cognitive existentialism is not irrelevant in respect to political reflection and socio-cultural engagement of science. What if a hermeneutic strategy simply is not the best option?

Consider again Georgia Warnke’s $(2003,116)$ insight: "Hermeneutics itself requires skepticism about some interpretations, namely, those that require or lead to the elimination of others, and it requires this skepticism in order to enhance the expression of all those others". Is Ginev's a kind of "some interpretations" we should be skeptical about? Surely it does not belong to the Rortian space, absent of constraint and confrontation, but it ambitiously pursues contribution to the democratization process as an edifying discourse. The philosophy of scientific practices, also being a kind of politico-philosophical initiative, aspires to critically assess particular discursive practices of sciences as an ongoing engagement with specific social, political, cultural, economic contexts and simultaneously denies the very possibility to politically assess science as a whole; therefore ostensibly "marginal" parts of science (e.g. military technologies, agriculture, practices of medicine) that explicitly show the socio-political content of discursive scientific practices is of major importance in the philosophy of scientific practices. At that point, Ginev $(2005,198)$ raises his

main political objection against the politics of postmodern philosophy of science: to demolish the demarcation line between the cognitive self-organization of scientific research and the socio-political contexts in which the research practices take place amounts to committing a false image of democracy. The genuine democratic process of contemporary societies needs science's cognitive autonomy. Otherwise, these societies will be totally instrumentalized: science's complete contextual instrumentalization will imply a scientification of social life. 
What this "genuine democracy" is, Ginev does not specify. However, this would mean that the program of cognitive existentialism is also a political alternative of hermeneutics of science, vigilantly protecting the society from the instrumentalization and scientification the postmodern condition emits. But where does that "politics" take place? Since it cannot be based on sociopolitical medium, one has to rely on established principles of hermeneutical methodology, namely Heideggerian ontico-ontological distinction and the concept of "translatability": no external (political, social, etc.) factors can influence the cognitive content of science, until transferred into intrinsic "hermeneutical circles" of the constitution of that content, in other words, until they are incorporated into the internal interpretive "fore-structure" of research process.

\begin{abstract}
The natural sciences are resistant to external influences (and able to maintain their cognitive specificity) not because their research process is a non-interpretative enterprise, but because of the potential of translatability they demonstrate in each particular historical situation. Their cognitive specificity has to be defined first and foremost with respect to the intrinsic hermeneutic circles constituted by that ongoing translatability which prevents the 'ideologization', 'metaphysical finalization', or 'political manipulation' of the research process. Science maintains its cognitive autonomy not through isolation by implementing procedures of idealization, but by means of interiorization based on ongoing translatability. (Ginev 2006, 21).
\end{abstract}

But if you agree with the latter, it seems that there is no danger of instrumentalization of modern society at all. I think that the likely translation of the basic idea of cognitive existentialism is that science is autonomous per se, and the only threat endangering the autonomy of science is a nondemocratic, neo-pragmatist mode of quasi-understanding, attempting to infect the innocence of scientific enterprise with instrumentalist ideology.

\title{
5. Conclusion
}

So what are the threatening elements of philosophical discourse, alien to polylogical philosophical and political public sphere? If we recur to the previously mentioned options of hermeneutics of science, we thereby must consider two modes of its engagement, or types of intertwining of hermeneutics and science: one is the mode of hermeneuticism represented by a more decent version of hermeneutics of Heelan and a rigorous version of cognitive existentialism of Ginev, both subsumed under option B, and the other mode proposed by "non-philosophical" Rorty and Rouse. According to the first one, hermeneutics, as Algis Mickunas wittily remarked, carries out its historical mission, and by examining scientific theories and practices, the 
masterworks of high culture, assumes the obligation to transmit this cultural knowledge into the everyday context, that is, is engaged in scientific journalism, and seeks to give a sense to secret symbolic formulas of scientific community's high priests (Mickunas 2007, 64).

The other mode is the problematization of excessive hermeneuticism, a moderate type of hermeneutical engagement that underlies practical conditions of any state of knowing and cultural presence.

\section{Bibliography}

Crease, R. (1997). Hermeneutics and the natural sciences: Introduction, Man and World 30: 259-270.

Fuller, S. (2003). The unended quest for legitimacy in science, Philosophy of the Social Sciences 33: 472-478.

Ginev, D. (1998). Rhetoric and double hermeneutics in the human sciences, Human Studies 21: 259-271.

Ginev, D. (2005). Against the politics of postmodern philosophy of science, International Studies in the Philosophy of Science 19: 191-208.

Ginev, D. (2006). The Context of Constitution: Beyond the Edge of Epistemological Justification, Springer.

Ginev, D. (2007). A (post)foundational approach to the philosophy of science: Part ii, Journal for General Philosophy of Science 38: 57-74.

Heelan, P. (1997). Why a hermeneutical philosophy of the natural sciences?, Man and World 30: 271-298.

Heelan, P. (1998). The scope of hermeneutics in natural science, Studies in History and Philosophy of Science 29: 273-298.

Heelan, P. and Schulkin, J. (1998). Hermeneutical philosophy and pragmatism: A philosophy of science, Synthese 115: 269-302.

Mickunas, A. (2007). Permanency and Flow: Outlines of Phenomenology of Culture, KFMI, Vilnius. in Lithuanian.

Rorty, R. (1979). Philosophy and the Mirror of Nature, Princeton University Press, Princeton.

Rouse, J. (1991). The politics of postmodern philosophy of science, Philosophy of Science 58: 607-627.

Rouse, J. (1996). Engaging Science: How to Understand its Practices Philosophically, Cornell University Press, Ithaca. 
Rouse, J. (2002). How Scientific Practices Matter: Reclaiming Philosophical Naturalism, University of Chicago Press, Chicago.

Warnke, G. (2003). Rorty's democratic hermeneutics, in C. Guignon and D. R. Hiley (eds), Richard Rorty, Cambridge University Press, Cambridge. 